\title{
The Mechanism of Approval Seeking Posting Guided by Present SNS Analysis
}

\author{
Taishi NEMOTO *, Takayuki FUJIMOTO *
}

\begin{abstract}
In late years, the use of social media, especially social networking service (SNS) is prevailing with the increase of the smartphone users. As a characteristic of SNS, every user can share or diffuse information in real time by casual message postings. There are more than several hundred kinds of SNS, and the popularity is clear. Facebook has the largest number of the users in the world, and its monthly active users (MAU) are more than 20 billion. SNS is the latest medium and is also a convenient tool for information transmission judging from information-gathering history, however SNS has an aspect specialized in the self-expression seeking something "Instagrammable". This is because SNS works as a haven for people's approval desire and the self-expression, and that user property trim SNS's convenience mainly. The unnecessary informational noise is inevitable in information-intensive society by all means, and the making SNS more helpful as the intelligence tool that can automatically filter the noise is needed. However, the definition of what is the approval seeking expression is vague and whether it is necessary or unnecessary is up to each user. From the different point of view, it is also a fact that there is overflow of information which looks useless and nothing but self-expression, and there are no needs for. In this paper, we focus on the approval seeking posts that are often seen on SNSs and demonstrate the mechanism and examples.
\end{abstract}

\section{Introduction}

Recently, the use of social media is dramatically prevailing with the spread of smartphones. The social media can transmit a large quantity of information fast using the Internet. Specifically, the increased use of SNS is remarkable combined with spread of smartphone. In addition, it is supposed that if the number of the people who use the same media increases, opportunities of communication increases as well, and it results in the further increase of the users by a snowball effect.

However, as for the increasing SNS users around the world, most of them are using multiple SNSs differently. It is as a matter of course, because there many kinds of SNS. Comprehensive type SNS, messenger SNS, and picture sharing SNS, all have different usages.

Whereas SNSs are convenient for information sharing or gathering, it goes without saying that

\footnotetext{
* Toyo University, Tokyo, Japan
} 
much unnecessary information is included in a number of the users' postings. There are some controversial examples of the postings with false information or uncertain information. There are a large number of the users who perform "communication without content", when we focus on a recent trend. "Communication without content" means communication that people perform when there is nothing to do in particular. We cannot deny how this communication is, however it is certain that this type of communication is spread on SNSs and reducing the efficiency for information gathering.

\section{Background}

So-called a SNS pioneer in a narrow sense, Friendster was developed in 2002 and it offered the service upon which the users could search friends and maintain their contacts. Afterwards a lot of SNSs started their services. Nowadays there are many types of social media, particularly SNSs. It is not easy to catch on to the SNSs in fashion, and to join them, because everyone at present does not use one same SNS and selects the SNS that suits him or her. The choices are different depending on area, age or preference of the user. The media type of SNSs are also various, for example there are SNSs on text-basis and photograph-basis.

The number of the users who keep distance from a convenient tool increased and it is called "SNS fatigue." It is a reversal phenomenon that users who used SNS to satisfy a social desire to be connected to the person is tired of SNS. The users who utilize SNS to obtain information instead of to connect to others are also seen in various sites.

\section{Purpose}

We suppose that SNSs have much unnecessary information or postings. To solve this problem, in this paper we aim to examine whether SNSs are effective for information gathering by arranging and analyzing present SNSs.

Regarding the change of information-gathering method from the age before the Internet to these days, the interactive quality of media has more impact than quantity and the speed.

It is so-called "Sharing" in the Internet age. It became easy not only to obtain information, but also to transmit information by technological advancement. In addition, what's called "spread of information" became easy. It can be said that after all information gathering in the age of information spreading is also to be done on SNSs. SNS is the most advanced tool for the information collection, which human beings have engaged in for a long time.

When it comes to information volume, search engines are effective, however the biggest reason why SNSs are used for information gathering include the timeliness. The instantaneous information like disaster information such as earthquakes, and delay information of the train is suitable for SNS.

We classify that type of information and remove posts that meet the conditions as unnecessary information. With this method, it is supposed that the SNS will become more effective information-gathering tool not just for simple information sharing. There are plenty of unnecessary postings that is too private for most people on SNSs. From the point of view for information sharing, their influence is so inefficient that we cannot use SNSs properly for information gathering.

However, there is certain number of the users who want the very private information. Therefore, instead of deleting the unnecessary information, we filter it by a new display method. There is an approach not to follow or to block the users who are the source of unnecessary information for 
efficient information gathering. This study proposes the system that automatically filters information instead of users' settings for filtering with a word or multiple words. Unnecessary postings focused on this study are the postings with approval desire. They are widespread self-satisfactory content posted on SNSs. They occupies much of "communication without content", and it is supposed that the usefulness of this information is quite low.

We assumed that efficiency of information gathering can be increased by relieving the influence from these postings with approval desire on the SNS.

\section{Characteristics of SNS}

A) Transmission of information and media

Although people are always exposed to information, the practical information that they actually use is limited. Whether information is useful or not is up to a user, and the media has been developed mainly to convey important information. "The communication without content" was thereby born at the same time. "Communication without content" means using the media though there is not the need in particular. Here is the example: "What are you up to now?" "I am bored." "Communication without content" has spread matching the appearance of the IM (instant message), people's busyness and change in the people's sense of values. The remarkable example is Twitter. The simple social media with 140 character-limit, on which the user can start communication, explosively increased the number of the users with the appearance of the smartphone.

B ) SNS' availability for information gathering

The information gathering on SNSs is more passive than the search by the WEB browser. However, the users can obtain information that they want effectively by narrowing down sources of information appropriately.

The teenage users are called "smartphone native", and there are many youths using SNS instead of search engines for information retrieval using the Internet. This is because most of them tend to need instantaneous information. The search using the hashtags is particularly supported because the information relevant to the keywords appears with high probability. SNSs are gradually taking on the aspect as the search platforms. This is because when a smartphone native generation started to have smartphones, SNSs already spread and they chose SNSs as the main media. They use some SNSs differently depending on usages; Twitter for news and trends, Instagram for fashion and restaurant by search with hashtags

\section{Analysis}

\section{A. The present main SNS}

The kinds of SNSs used recently are enormous. There are social media with which genres or themes have been already decided, and also the related areas or purposes are limited. In this study, we mainly analyze SNSs that have a significant number of the users and are recognized world widely. QQ, WeChat, Qzone from China have a large number of users because China has a huge population. However, since they are not used globally, we do not deal them. The following is the number of the users of each SNS. 
Table 1: SNS dealt in this paper

\begin{tabular}{|c|c|c|c|c|c|c|}
\hline & $\begin{array}{r}\text { Release } \\
\text { your }\end{array}$ & MAU & $\begin{array}{l}\text { Main } \\
\text { Media }\end{array}$ & Cotedarias & Timeliness & Volume \\
\hline Facobook & 2004 & 20billion & text & $\begin{array}{c}\text { comprehen } \\
\text { sive }\end{array}$ & $\triangle$ & (2) \\
\hline twitter & 2006 & 3billion & text & $\begin{array}{l}\text { comprehen } \\
\text { sive }\end{array}$ & (c) & 。 \\
\hline Instagram & 2010 & 8billion & picture & $\begin{array}{l}\text { Picture } \\
\text { sharing }\end{array}$ & (8) & $\Delta$ \\
\hline Pinterest & 2010 & 2billion & image & Picture. & $\Delta$ & 0 \\
\hline Linkedin & 2003 & 5billion* & text & business & $\triangle$ & (9) \\
\hline Googlet & 2011 & 5bllion & text & $\begin{array}{c}\text { comprehen } \\
\text { sive }\end{array}$ & $\Delta$ & 。 \\
\hline WhatsApe & 2009 & 10billion & text & messenger & 0 & 。 \\
\hline LINE & 2011 & 2billion & text & messenger & (2) & 。 \\
\hline Snapchat & 2011 & 2billion & picture & $\begin{array}{l}\text { Picture } \\
\text { sharing }\end{array}$ & 0 & $\triangle$ \\
\hline Tumblt: & 2007 & 5 billion* & text & blog & $\Delta$ & () \\
\hline
\end{tabular}

\section{B. Analysis}

We consider which SNS is most suitable for information gathering out of present SNSs. Facebook, LinkedIn and Tumblr have much information per one post, and Twitter, Instagram and LINE are for instantaneous information. It is supposed that this real-time attribute is necessary as well as information volume for information gathering on modern SNSs. In particular, because a certain number of the youths need instantaneous information and perform searches on SNSs instead of using the search engines, it is assumed that the SNS that has rich real-time information will be in higher demand in the future.

In addition, the rise of the image sharing types of SNSs, which are popular among youths are outstanding now. Instagram, Pinterest, and Snapchat was released after 2010, and the fashionable touch is the key of popularity. The SNSs on photograph-basis enables easy uploading than the ones on text-basis and they also allow easier and quicker viewing. Because of the photo editing functions such as filters, the users can create impressive photographs with friends.

Regarding Snapchat the user can set the limit of viewing time in the range of 1-10 seconds and as to Instagram Story, the user can set the limit of viewing time of 24 hours, and this real-time attribute goes over well. The number of Instagram Story users have already surpassed 200 million people and one quarter of Instagram MAU, 800 million, use it. It is a successful example of "disappearing SNS". It brought the new idea to delete information instead of recording information. In regards to the messenger applications such as WhatsApp and LINE, the voice call function is a strength. The simple interface like SMS board drove the responsive chat with the quicker replies and increased the number of the users. In respect of information volume, the points by which LINE is superior to WhatsApp is the news curation and the implementation of timeline that is originally on other SNSs. WhatsApp seems to be mainly for one-on-one communication. Facebook, the parent company may aim at the use different from Facebook and Instagram strategically. The total number of the users is more than 5,500 million people and it leaves other SNS company behind a wide margin.

Tumblr. established the position as micro-blog SNS. It is increasing the number of the users steadily. Because the characteristic of Tumblr. is considerably different from other SNSs, even if 
the base of the users overlaps, it does not matter at all. It is an important problem for Tumblr. whether it will be able to spread as a substitute for the WEB site in the future.

If we categorize 10 SNSs listed up, they are divided into four groups. Four groups are comprehensive type, picture sharing type, messenger type, and theme type. In fact, the age groups of the users are different depending on these categories. The user bases of the comprehensive type, the messenger type, and the theme type resemble closely, according to this classification. The basic user groups of the social media seems to overlap these bases. On the other hand, regarding photograph sharing type, the age of users is much younger. There are the user group over thirties, however these types of SNSs are used among teens and twenties outstandingly. Photographs and movies that is understood at a glance seems to be well accepted. Particularly, the rate of the young users of Instagram and Snapchat is almost twice as the rate of the other age groups.

\section{The advantage in information gathering}

We have supposed that the effective information gathering requires to remove unnecessary or unimportant information and to display only information considered to be useful. However, what is important for information gathering is not only effectiveness. The variety of information is also necessary for information gathering. It is important that the user can obtain the unexpected new discovery, which he or she has not known before, when checking information on particular fields on SNSs. As for searching something new instead of searching already-known information within expectations, some variety is required in information sources. Because there is much information, SNSs and the Internet have the variety. There is plenty of needless information on SNSs, however there is also much possibility of new discovery for this point. In order to take advantage of this informational variety on SNSs, it is important to customize how to display the information by a different approach from the usual way. There is a research findings that the variety of the information promotes people's generating ideas, however it rather disturbs idea generation when there is too much completely irrelevant information. In other words, we reached the conclusion that it is best to maintain information variety on SNSs while applying filtering.

\section{Approval Seeking Postings}

These days, there are innumerable postings on SNSs. The users have tendency to send postings with content to satisfy his or her approval desire. The postings are the outputs of the user's self-satisfactory feeling and they are not communication of useful information with others. Those postings do not require either information sharing or development. The modern SNS users repeat to transmit extremely private postings. This is because the action can satisfy their casual approval desire through SNSs. SNS seems to give the users further approval desires by showing the number of "like!" or the followers, which meets the users' approval desire, however the users compare it with other users' at the same time.

The approval desire is the highly advanced desire next to self-realization upon the five phases theory of Maslow. In the present age when the infrastructure is developed to some extent, there are a large number of people who can connect to the Internet. The appearance of the approval desire in the communities on SNSs may be relatively a natural phenomenon. SNSs have high particular affinity for showing off and they are used as the tools to easily satisfy the approval desires, however that kind of information does not mean a lot. Most of the information is conveyed for the narcissistic purpose to attract people's attention. What was just an "update" can transform to the method to catch the others' replies or to gather people's attention without even noticing. It is not exaggeration even if we say that SNSs have enlarged people's approval desires.

This enlargement of the approval desires is a problem for the information gathering on SNSs. 
Particularly, comparing the approval desire with other person's is easy on SNSs. The postings with the approval desire can be spread easily, and they are frequently used as the tool to meet one's showing off. The scattered postings with the approval desire will generate the further approval desires again in a vicious circle. In the following table, we applied the desire zone theory of Maslow as real world (offline) to the online communities.

\begin{tabular}{|c|c|c|c|}
\hline \multirow{6}{*}{ 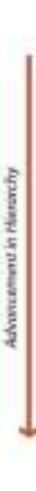 } & Need & Offine (Maslow) & Online Communities \\
\hline & Physiological & Food clothing, shelret, health & $\begin{array}{l}\text { System acoess; the ablity to own } \\
\text { and maintain one's identity while } \\
\text { participating in a web community }\end{array}$ \\
\hline & Security \& 5afety & $\begin{array}{l}\text { Protection from cimes and war: } \\
\text { the sense of living in a fair and } \\
\text { just sociery. }\end{array}$ & $\begin{array}{l}\text { Protection from hacking and personal } \\
\text { attacks; the sense of hwving a "level } \\
\text { playing feld"; abiity to maintain } \\
\text { varying levels of privacy }\end{array}$ \\
\hline & Social & $\begin{array}{l}\text { The ability to give and receive. } \\
\text { love: the feeting of belooging to } \\
\text { a group. }\end{array}$ & $\begin{array}{l}\text { Belonging to the commurity as a } \\
\text { whole and to subgroups within the } \\
\text { community. }\end{array}$ \\
\hline & Self-Esteem & $\begin{array}{l}\text { Self-erpect the ability to } \\
\text { earn the respect of others and } \\
\text { contribute to society. }\end{array}$ & $\begin{array}{l}\text { The ablity to contribute to the } \\
\text { community, and be recognized for } \\
\text { thase contributions. }\end{array}$ \\
\hline & Self-Actualization & $\begin{array}{l}\text { The ability to develop skils and } \\
\text { fuifil one's potentsal. }\end{array}$ & $\begin{array}{l}\text { The ability to take on a corrmunity } \\
\text { role that develop sklis and opens up } \\
\text { new opportunities. }\end{array}$ \\
\hline
\end{tabular}

Figure 1.:Maslow's hierarchy of needs for communities

What we should pay attention to is the line of Self-Esteem. "The ability to contribute to the community, and be recognized..." is described. The SNS users demand that their existence is recognized by repeating postings to online communities that they belong to. It is modern Self-Esteem. "contribute" can mean "write" or "post" in some contexts. The user can contribute to the SNS community.

Besides, SNS is also available not only for meeting the approval desire but also for satisfying the position desire. For example, when someone send the posting about the hot topic, it becomes an even hotter topic, and a group of people can share one story. The user can be connected to the unspecified number of the users on SNSs. This is the example of the position desire. There is an aspect in which the youth who cannot satisfy this position desire in real life is trying to meet the approval desire on SNSs. Particularly for young people, the approval desire is essential to the self-formation. It is certain that there are many users who use SNSs to satisfy their approval desires, which they cannot handle.

In this respect, SNSs and the approval desires have strong affinity. The desire to be accepted by others and the desire to connect to people are closely related each other, and they are the main reasons why people use SNSs. This is the mechanism that makes the users update the approval seeking posts. Of course the two kinds of desire are also associated with general posts, however their relevance is remarkable with the approval seeking posts.

\section{Example of Approval-desire}

The approval seeking types that can be a problem for information gathering on SNSs include the following items.

(1)Nuanced form such as emojis and decorative characters

Because the emojis or the decorative characters are expression methods, they have no informational values by themselves. It is effective to represent the objects or feelings in simple way, however it is supposed that they are not worthy for information gathering. There is a SNS called 
"emoji" for which only the decorated letters are used, however, it is not practical enough to use information gathering at present. The following are screenshots of emojis.

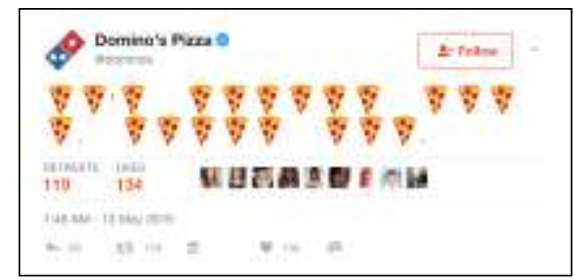

Figure 2: emoji screen

It takes time to interpret content. It is now the inefficient media because accurate information cannot be obtained. Communication imperfection may be caused. They are new as an idea, however they go against the history of the letters development.

(2)Abuse of hashtags

Originally the hashtag is a function for a search and a classification. When we look for the same information or similar information, it can work helpful, however, the hashtags are actually used differently nowadays. Specifically, the usage to make hashtags too long or add too many hashtags is not useful at all for proper classifications.

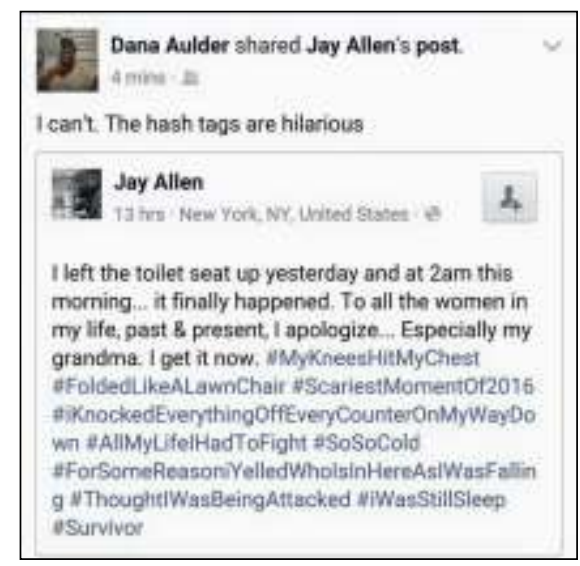

Figure 3: example of much hashtag

They probably abuse hashtags for an ease to come up with a search, however there is little information provided with them.

(3)Link to the purchase sites

This is the typical model for the commercial use of SNS as a tool for the advertising. Certainly there may be the useful information, however the information of the product is not provided well and the main focus is to make the users purchase the product. Thus, they are unnecessary for information gathering. There are many users who use SNSs for advertising or branding, however those advertising cannot work as the useful information. The reason is because that SNSs have basically very real-time information. The good point of SNSs are information that is delivered immediately, variety, and the volume of information. The links to the representative purchase sites of the advertising postings can be often unpleasant for the users. 
(4) Links to other SNSs

This is an activity to double self-expression. For example, it is double self-presentation to upload the same photo as the one posted to different media: to send twitter the photograph that the user has posted to Instagram. It is meaningless to duplicate the same information and that is different from reuse of information. The recent SNS users utilizes SNSs differently depending on purposes. It does not seem that linking those SNSs used for the different purposes by the same postings have any meaning.

(5)Emotional content and the terms to imply "fulfilled offline life"

The SNS users can post what they want to write freely. With the search by the word, "tired", various users' complaints about fatigue or the dissatisfaction come out. The coherent message, "tired" itself does not imply much meaning, and it seems that the user post the comments to get people's attention through the word, "tired".

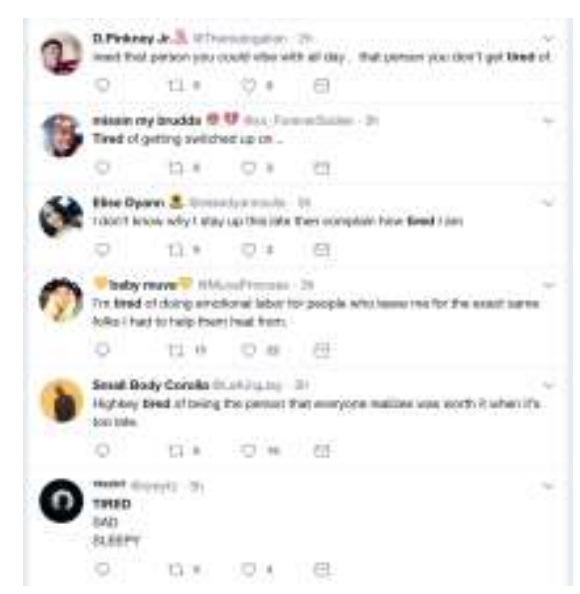

Figure 4: search results of "tired" on Twitter

Of course talking about the private life may be necessary in some conversations. However, it is often the case that the extremely private content is uncomfortable with other users. For example, here are two postings: "I watched the latest movie yesterday, and was moved to tears." and "I quarreled with a boyfriend in a trifle, and cried yesterday". The actions of "crying" are the same, however each user's viewpoint is greatly different. The former's theme is a movie, and the latter's is "I" or "my boyfriend". "I" am a word to imply showing off, and "the boyfriend" is a word to be associated with "Riajyu". "Riajyu" is the Japanese term to indicate a person who lives the fulfilled offline life. The implication of the posting: "quarreled with my boyfriend" is a roundabout expression to appeal the fact that she has a boyfriend. It can be said that this cryptic manner or custom of show-off is rather unique to Japan.

(6)excessive space and line breaks

Spaces and the line breaks make information easier to read, however they themselves do not have the meaning. The postings full of letters have more information. Using too many spaces extend the posting view, which covers the space for other information. It is a typical model of craving the limelight. 


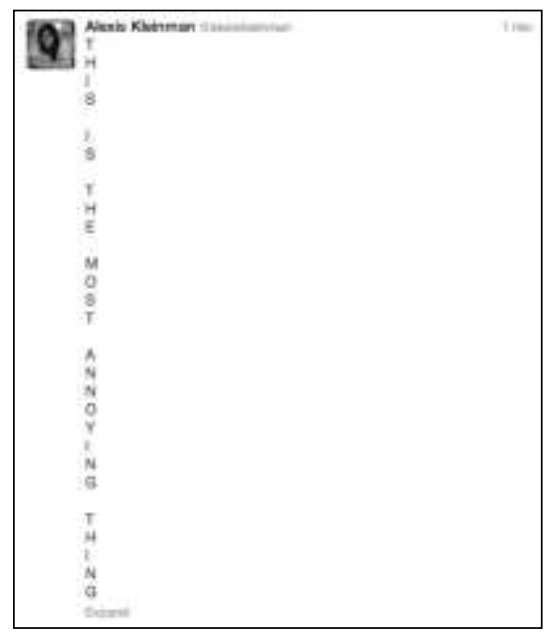

Figure5: post on SNS

It rarely happens that too many linebreaks work effective. There is the example that people calls postings with too many linebreaks and punctuation "poem SNS". It seems that sometimes postings to with too much appeal based on one's own world can be annoying on SNSs, which are supposed to be the place for socializing.

We listed these six types, as examples of the approval seeking postings.

\section{Conclusion}

We analyzed present SNSs and focuses on the approval seeking postings that is regarded as the problem to be solved and demonstrated the examples. The postings on SNSs based on Maslow's hierarchy of needs stand to reason, and the users tend to update the approval seeking posts easily. Taking the approval seeking posting examples into consideration, it is the present condition that most SNSs are used for communication among people rather than for information gathering after all. On the other hand, it is reasonable that the users can also use SNSs as a tool for information gathering. It is necessary to target sources of information appropriately for information gathering. Specifically, the users have to choose the users to follow by themselves and narrow down information to only the information in their needs. It seems that this method is like the choice of older generation. It is too inefficient to pick up necessary information after having laid a large quantity of information in stock indiscriminately. Therefore, a new form of SNS as a information gathering tool for the next-generation is required in the future. For example, the SNS for the next-generation does not just recommend information that a user may want. It also quantify values of information. There is "season" for the instantaneous news, however the reuse method of the information out of its season also must be considered.

In addition, "disappearing SNS" has certain impact on impression. There is a great need for deleting information daringly instead of collecting information and keeping it as a record. The need for deleting-information is reflected to Instagram Story, Snapchat, and Snow mainly. These SNSs are interesting to catch each moment of daily lives, and they rather have strong entertainment touch. It is difficult to judge whether these types of SNSs are the temporary fashion or the appropriate form of evolution. As the future task, the system which classifies so-called "unnecessary information" and relieves its influence is required. For that, we need to clearly define what the approval seeking post is. The interactive property of the Internet is suitable for 
information sharing. However, unnecessary information and the wrong information also appears on SNSs. Whether information is unnecessary or favored depends on every user and we cannot make a sweeping judgment. However, it is possible to extract information to some extent. It is assumed that the function that automatically extracts useful information and information which the user may want is needed. We can improve quality of SNS communication by disabling the display of unnecessary information that is seen in casual communication.

Because the approval desire is a human's basic desire, it is expected that the SNS users continues to update the approval seeking posts as a haven of its expression. Reducing the number of the steps of the information evaluation process that the users originally have gone through by quantifying value of information remains as a problem to be solved in the future. The social media such as SNSs have brought high effectiveness in people's information gathering, and further improvement of efficiency is also required for the SNS of next-generation.

\section{References}

[1] KEISUKE IRIE, TATSUO NAKAJIMA, "A study on a framework that promotes high-quality information generation of CGM user”, DICOMO2016, 687 - 694P.

[2] "A Study of Japanese Young People's Self-Disclosure and Emotional Expression over SocialNetworking Sites- Content Analysis and Interview with Twitter and Facebook Users", http://www.jsicr.jp/doc/taikai2014/a1-muramasu.pdf, 2018.

[3] Tsutomu Ikemura,"The Proposal of a Measure on a Youth's SNS Use Tendency and Problem", 「Hokuriku Gakuin university bulletin」Vol7, pp. 281-288, 2014

[4] Akiko Orita, Specialfeature, "How and what to use social service . SNS provides networking and lifelog”, https://www.jstage.jst.go.jp/article/jkg/61/2/61_KJ00007018024/_pdf/-char/ja, 2011 .

[5] Yoshinobu Yamamoto, Next-generation communications media, considering the evolution, http://www.submit-asap.org/home/yoshinov/library/IEICE_HCS201003.pdf, 2018

[6] "Reach of selected social networks in the United States as of February 2017, by age group", https://www.statista.com/statistics/305245/us-social-network-penetration-age-group/, 2017.

[7]Marketing Research Camp, "Information Gathering of teens on SNS" https://marketing-rc.com/report/report-monthly-20170308.html, 2018.

[8] “The history of SNS”, https://www.jstage.jst.go.jp/article/bplus/9/2/9_70/_pdf, 2018.

[9] Information Science and Technology associations, https://www.jstage.jst.go.jp/article/jkg/63/1/63_KJ00008427320/_pdf/-char/ja, 2018.

[10] Fujimoto Takayuki, "Design that makes information easy: What is information design and what is not information design", 「Information Science and technology Vol.65, No.11, pp. 450-456, 2015.

[11] William Song, "A Semantic Approach to Internal Structure Formation in the Semantic Grid," Proc. Third Int'l Conf. Semantics, Knowledge, and Grid (SKG 2007), CD-ROM, IEEE CS, 2007, pp. 248-253. 